Bond University

Research Repository

\title{
Importance of Ability-Based Training for Law Enforcement Recruits
}

Lockie, Robert G.; Dulla, Joe; Orr, Rob Marc; Dawes, Jay

Published in:

Strength and Conditioning Journal

DOI:

10.1519/SSC.0000000000000583

Licence:

Other

Link to output in Bond University research repository.

Recommended citation(APA):

Lockie, R. G., Dulla, J., Orr, R. M., \& Dawes, J. (2021). Importance of Ability-Based Training for Law

Enforcement Recruits. Strength and Conditioning Journal, 43(3), 80-90.

https://doi.org/10.1519/SSC.0000000000000583

\section{General rights}

Copyright and moral rights for the publications made accessible in the public portal are retained by the authors and/or other copyright owners and it is a condition of accessing publications that users recognise and abide by the legal requirements associated with these rights.

For more information, or if you believe that this document breaches copyright, please contact the Bond University research repository coordinator. 


\section{Importance of Ability-Based Training for Law Enforcement Recruits}

Key words: academy training; individualization; job-specific fitness; police; tactical strength and conditioning 


\section{SUMMARY}

A number of research studies have indicated a wide variation in the physical fitness of law enforcement recruits prior to academy training. This paper provides a literature review regarding current training practices, and the associated limitations, specific to recruits during academy. Collectively, this information indicates the need for ability-based, individualized training for recruits during academy, which is not always the model adopted for a variety of reasons. Practical applications relative to this analysis, in addition to examples for aerobic/anaerobic conditioning and resistance training programs, are presented. These programs feature exercises that that are modifiable depending on the fitness of recruits.

\section{INTRODUCTION}

Law enforcement is a physically challenging profession. Many of the tasks performed when onduty demand a high muscular force output, potentially for extended durations. For example, Dawes et al. (15) stated that officers may be required to push, pull, lift, carry, drag, jump, vault, crawl, sprint, and use force at any time during their shift. These actions can be expressed within jobspecific tasks such as driving vehicles (36), using firearms $(27,60)$, defensive tactics $(11,60)$, vaulting obstacles, civilian or partner rescue, and pursuing and apprehending suspects $(12,35,45)$. As a result of these physical demands, law enforcement recruits generally complete academy training before they can become sworn officers or deputies. During the academy training period, recruits learn the necessary procedures required for their job and agency, and complete training designed to mentally and physically prepare them for their profession $(9,32,35,61)$. 
Physical training is a major component of academy for recruits. Not only can physical training be used to develop fitness $(9,10,30,61)$, but it can also be utilized to impose psychological stress and discipline in recruits $(3,34)$ and, in excess, may increase injury risk (71). As for any exercise program, the ultimate goal is to enhance the fitness and physical capabilities of the trainees. The approach taken during law enforcement academies has often resembled paramilitary-style training $(6,24,32,39,54,61)$. However, this may not be the most optimal approach for developing physical fitness in law enforcement recruits. As law enforcement agencies (LEAs) will take their recruits from the general population there are a wide range of fitness capacities present in the adults who are accepted into the law enforcement profession $(39,42,48)$. A further consideration is that many agencies are attempting to increase the diversity of their workforce, which often includes a greater focus on the recruitment of women $(19,74)$. This approach is of note given that the results from numerous studies have indicated that female recruits, in general, have a lower level of fitness than male recruits across a range of different fitness assessments $(4,5,7,14,37-39,43,44,46)$ and lower levels of fitness are associated with an increased risk of injury (71) and graduation failure $(13,32,68)$.

This paper will discuss the importance of individualizing training for law enforcement recruits by including ability-based modifications. Individualized training involves designing the program such that it is appropriate for the person relative to their strengths, limitations, and physiological responses to exercise (21). Training practices commonly used in law enforcement academies will be reviewed, and research that demonstrates the great variability in fitness for law enforcement recruits prior to the academy training process will be documented $(39,42,48)$. These studies will illustrate the range of fitness capacities present in law enforcement recruits in muscular endurance 
and strength, and anaerobic and aerobic capacity. Finally, potential strategies LEA staff could take to individualize training will be presented.

\section{CURRENT TRAINING PRACTICES AND LIMITATIONS}

As officers from different LEA can vary in levels of fitness (56), the physical (and general) training requirements for law enforcement training academies in the USA can vary by city, county, and state. Some agencies conduct their own academies, others may send their candidates to specific training centers or community colleges for their training. In the USA, law enforcement training academies can take place over a period of almost 6 months $(9,32,35,43)$. Depending on the agency or facilities, recruits may have a live-in situation where they stay on-campus (24), or they may need to travel to and from home to the academy. Within this time period, recruits receive training in a number of different areas. There are academic requirements, scenario-based based training, physical training, and the training and testing of job-specific skills (32). The physical training is typically directed towards improving fitness, in addition to enhancing the qualities important for job-specific tasks. Many recruits will need to complete a physical, job-specific exit examination before they can graduate academy. For example, in the state of California, recruits must complete the Work Sample Test Battery (WSTB) before they can graduate $(35,45,63)$. The WSTB consists of five tasks completed for time: a run around a 99-yard (90.53-m) obstacle course; a body or casualty drag with a 165-pound (74.84-kg) dummy; a climb over a six-foot (1.83-m) chain link fence; a climb over a six-foot solid wall; and a 500-yard (457.2 m) run (35,45,63). As muscular endurance, anaerobic capacity, and aerobic fitness underpin the actions within the WSTB (35), recruits would benefit from enhancing these qualities during academy. 
Many law enforcement training academies operate via a paramilitary, 'one-size-fits-all' training model $(6,24,32,39,54,61)$. The expectation from this model is that all recruits should complete the same exercises, with restricted individual modifications relative to exercise type, work-to-rest ratio, volume, intensity, and load. The paramilitary training model is in part used because the job tasks of all officers are the same, regardless of sex, age, and to an extent, physical ability. Development of fitness is one goal with paramilitary-style training. However, a secondary goal that the strength and conditioning coach (if they are working alongside the law enforcement training staff responsible for the recruits) must be aware of is the socialization aspect of physical training for law enforcement recruits (3). To an extent, this may override what may be considered best practice for fitness improvements. However, there are some limitations associated with this training model, especially considering the range of physical fitness characteristics present in recruits $(42,48)$. This approach may cause recruits of differing ability levels to receive inappropriate training stimuli for the desired training outcome (54).

Previous research conducted by Orr et al. (61) compared an ability-based running program approach versus a traditional running program in Australian police recruits across two training blocks. Although there were no differences in improvements in aerobic fitness as measured by the 20-m multistage fitness test, there were differences in injury rates. In the first training block which featured 54 recruits, 4 recruits (14\%) who completed traditional running training were injured, while only 1 recruit (4\%) from the ability-based running program was injured. In the second training block which had 233 recruits, 12 recruits (10\%) in the traditional running group suffered an injury; only 7 recruits (6\%) in the ability-based running group were injured. Orr et al. (61) noted that the difference in injury rates could save an agency up to $\$ 680,000$, due to the reduction in 
potential ongoing medical treatment and compensation costs. This study provides an example of the value of using training practices that are directed towards the current capabilities of the individual. Some of the factors that could contribute to the increased risk of injury for traditional paramilitary training includes greater running mileage (72), and recruits working at an intensity above their current capabilities (26).

Higher injury rates are a particular issue for female recruits $(26,29,64)$. For example, out of 426 male and 105 female Federal Bureau of Investigation agent trainees, Knapik et al. (29) detailed that females experienced a higher incidence of overuse (males $=5.6 \%$; females $=13.3 \%$ ) and traumatic $($ males $=31.2 \%$; females $=37.1 \%)$ injuries. However, it may be fitness differences, as opposed to sex differences, that explain the higher rates of injuries in female trainees $(29,64)$. Numerous studies have detailed that female law enforcement recruits and female officers typically demonstrate lower levels of fitness compared to their male counterparts $(4,5,7,14,37-39,43,44,46)$. For example, in testing conducted during initial hiring, female candidates were outperformed by male candidates in: number of push-ups (males completed $\sim 68-81 \%$ more repetitions) and sit-ups (males completed $\sim 11 \%$ more repetitions), and arm ergometer revolutions (males completed $\sim 20$ $21 \%$ more repetitions) completed in $60 \mathrm{~s}$; a 75 -yard pursuit (males were $\sim 8 \%$ faster); and the 2.4 $\mathrm{km}$ run males were $\sim 7-9 \%$ faster) $(4,7)$. In the week preceding academy, Lockie et al. (40) found that female recruits were outperformed by male recruits in the 2-kg medicine ball throw (distance: $\sim 6 \mathrm{~m}$ vs. $\sim 4 \mathrm{~m}$ ) and vertical jump (jump height: $\sim 54 \mathrm{~cm}$ vs. $\sim 38 \mathrm{~cm}$; peak anaerobic power: $\sim 4984$ watts vs. $\sim 3175$ watts; power-to-body mass ratio: $\sim 61$ watts $\mathrm{kg}^{-1}$ vs. $\sim 49$ watts $\cdot \mathrm{kg}^{-1}$ ), which were measures of upper- and lower-body power, respectively. Lastly, Lockie et al. (38) inferred superior aerobic capacity in male recruits prior to academy as measured by $2.4-\mathrm{km}$ run time $(\sim 11: 38 \mathrm{~min}$ : 
s vs. $\sim 12: 48$ min: s) and 20-m multistage fitness test shuttles completed ( 53 shuttles vs. 46 shuttles). It should be noted that Lentz et al. (31) found that for a one-unit increase in maximal aerobic capacity, female Canadian police officers were 1.59 times more likely to have an injury. Although this requires further investigation, Lentz et al. (31) suggested this could be related to exposure to other activities external to the job such as sport or fitness activities. Nonetheless, a one-size-fits-all training approach may mean that the majority of female recruits will be working at a relatively higher intensity for the same exercise when compared to male recruits, thereby increasing their risk of injury (26). This would seem problematic for LEAs that wish to hire and retain more female officers $(19,74)$.

The training modalities available to LEA staff and recruits can also vary greatly by agency. This is because academy class size, available equipment, and location can be limiting factors in the implementation of physical training $(6,54)$. For example, in analysis of three classes from one agency, Lockie et al. (48) found the cohorts included 67, 69, and 90 recruits. Attempting to conduct a group training session with 90 people is very difficult, especially if there is limited equipment and space. Depending on the number of LEA staff allocated to an agency, large class sizes may make it difficult to adhere to the recommended National Strength and Conditioning Association (NSCA) guidelines for professional-to-participant supervision ratios (1:20 for collegiate athletes) (69). As a result, LEA staff can often default to training modalities that are easier to conduct with limited equipment, such as body weight calisthenics and running.

These modalities may not be optimal for developing all the qualities needed for law enforcement job tasks. Body weight calisthenics and running training will primarily develop muscular 
endurance and aerobic conditioning (35). In a job task analysis survey, deputy sheriffs noted that dynamic strength, static strength, and anaerobic power were the most important underlying physiological constructs relative to their primary job tasks (22). Providing further evidence of this, Lockie et al. (33) found that maximum strength measured by the one-repetition maximum (1RM) hexagonal bar deadlift, and peak power measured by a linear position transducer, related to faster performance of the 165-lb body drag in male (1RM: $r=-0.666, p=0.003$; relative 1RM: $r=-$ 0.619, $p=0.006$; peak power: $r=-0.477, p=0.045)$ and female (1RM: $r=-0.754, p<0.001$; relative 1RM: $r=-0.535, p=0.022$; peak power: $r=-0.727, p=0.001)$ college-aged civilians. Moreno et al. (55) detailed that greater lower-body power as measured by a vertical jump (jump height: $r=0.209, p<0.05$; peak anaerobic power measured in watts: $r=0.568, p<0.01$; powerto-body-mass ratio: $r=0.489, p<0.01$ ) and standing broad jump (distance: $r=0.609, p<0.01$; distance relative to body mass: $r=0.426, p<0.01$ ) correlated with faster performance in the 165 lb body drag when performed by law enforcement recruits prior to academy training. As noted, the 165 -lb body drag is part or the WSTB for Californian law enforcement recruits $(35,45,63)$, so this task is recognized as being important for officers. Ideally, strength and power training would be a focus of academy training. How to include this, within the context of targeting the individual, is a challenge for LEA staff.

As previously stated, physical training during a law enforcement academy is also used by LEA staff to impart psychological stress on recruits $(3,34)$. Berg (3) noted that this approach is in part taken to socialize law enforcement recruits into the profession by establishing expected patterns of behavior, values, and attitudes. The imposed stress provided by the verbal commands of LEA staff is often designed to test the mental toughness and resilience of recruits, and find any character 
flaws that may impede being an effective law enforcement or correctional officer (e.g., displaying poor emotional stability in the face of adversity) (3). The verbal commands provided by LEA staff to recruits are continuous, very stern, and sometimes contradictory (34). Lockie et al. (34) noted that heart rate response to the imposed stress was equivalent to a vigorous exercise session, as custody assistant recruits attained a mean heart rate of approximately $80 \%$ of their age-predicted maximum during the first day of academy.

This training approach, while steeped in tradition and contextualized with future job performance, has some limitations with regards to improving fitness and reducing injuries for recruits. Not all individuals will respond well to this type of autocratic leadership and coaching (25). This could affect the learning of any new movements or exercises that are being assigned within a training session. Additionally, negative responses to autocratic leadership could contribute to a recruit voluntarily resigning from a LEA (32), especially those that get more emotionally upset, and are more tender-minded, carefree, and impulsive (17). Similar to the military, law enforcement recruits may over-exert and place themselves at risk of injury because they do not want to display weakness in front of their commanding officers (62). Furthermore, recruits may not report any injuries they experience as they do not want to get separated from their academy class.

\section{THE INDIVIDUAL RECRUIT}

The combination of psychological and physiological stress makes academy very challenging for recruits, notwithstanding any physical fitness limitations. This stress will generally be an inherent part of law enforcement training academies in order to prepare cadets for the stressors they will encounter on the job. The strength and conditioning coach should recognize that they may not be 
able to change many of the issues raised here. However, what the coach should recognize and emphasize to LEA staff is that their recruits are a mix of individuals with different capabilities.

There have been several studies conducted that have specifically analyzed the physical fitness of recruits by cohort or class. This is important, as the LEA staff or strength and conditioning coach does not have input on the type of recruit admitted to an academy class they are going to train; that is generally dependent on the human resources department of the agency (39). Firstly, Lockie et al. (48) investigated whether the fitness characteristics of recruits, as measured by five assessments (push-ups, sit-ups, and arm ergometer revolutions in $60 \mathrm{~s}$; 75-yard pursuit run; and 2.4-km [1.5mile] run) were similar across three classes. When considering the mean values for each class, there were no significant differences ( $p=0.091-0.458$ ), and Lockie et al. (48) suggested that this may have been due to the standard expectations for admission to a training academy (e.g. fitness tests, background checks, psychological evaluations). However, Lockie et al. (48) did note the wide range of recruit fitness as measured by the five assessments.

Lockie et al. (42) compared three custody assistant classes who, due to different hiring standards, tended to have lower levels of fitness when compared to deputy sheriff or police recruits trained by the same agency $(41,42,46)$. Similar to Lockie et al. $(48)$, there were no significant differences ( $p=0.093-0.998)$ between the three custody assistant classes when considering the overall mean values in four fitness assessments (push-ups and sit-ups completed in $60 \mathrm{~s} ; 201-\mathrm{m}$ [220-yard] run; and 2.4-km run). However, Lockie et al. (42) also provided individual fitness test scores for the 108 custody assistant recruits drawn from the three classes. These results showed the variation that existed between the custody assistant recruits. For example, push-up scores ranged from 0 
repetitions to 64 repetitions; sit-up repetitions ranged from 0 to 90 (42). The 201-m run had a slowest time of $95 \mathrm{~s}$, and fastest time of $25 \mathrm{~s}$, while the 2.4-km run had a slowest time of 31:35 min: s, and a fastest time of 9:59 min: s (42). On the basis of these results, Lockie et al. (42) recommended tailoring training to the abilities and current fitness levels of recruits, in order to ensure appropriate adaptations.

Most recently, Lockie et al. (39) analyzed 11 academy classes which incorporated 908 recruits (761 males and 147 females). A fitness assessment battery called the PT500 was analyzed, and comprised six assessments: push-ups, sit-ups, and mountain climbers completed in $120 \mathrm{~s}$; maximal number of pull-ups; 201-m run; and 2.4-km run. In contrast to previous research $(42,48)$, Lockie et al. (39) did find between-class differences in fitness assessment performance when considering overall class means. More notably, Lockie et al. (39) detailed a the wide range of fitness scores attained by the recruits. To provide some specific examples, the push-up assessment had a low of 0 repetitions, and a high of 113 repetitions. Pull-ups had a low of 0 repetitions, and high of 33 repetitions. Additionally, 119 females out of 147 completed 2 pull-up repetitions or less. For the 2.4-km run, the slowest time was 20:10 min: s, while the fastest time was 7:50 min: s; 85 out of 147 females completed the $2.4-\mathrm{km}$ run in 12:47 min: $\mathrm{s}$ or slower. These diverse ranges of scores demonstrate the high variability in fitness abilities that a strength and conditioning coach working with this population may need to accommodate when conducting physical training.

\section{PRACTICAL IMPLICATIONS}

Across the three studies $(39,42,48)$, what was clear was the wide variation in fitness as measured by muscular endurance (push-ups, sit-ups, mountain climbers, arm ergometer), upper-body 
strength (pull-ups), anaerobic capacity (201-m run), and aerobic capacity (2.4-km run). This also supports previous research detailing variation in individual recruit fitness levels between the sexes $(4,5,7,14,37,38,43,44,46)$. Further, the fitness assessment data presented by Lockie et al. $(39,42,48)$ was typical of that shown in previous law enforcement studies $(4,7,35,38,40,43,44,47)$. This indicates the practical application of the literature reviewed in this paper to other law enforcement populations. Indeed, this information could service as a guide for other agencies, LEA staff, and strength and conditioning coaches in their program design.

First and foremost, it should be recognized that LEAs would benefit greatly from the hiring of professionals specifically trained in strength and conditioning. Indeed, while some states and regulatory agencies may offer/require completion of state-specific fitness instruction courses, for LEA academy staff there is no validated or national competency standard or consistent requirements for continuing education or recertification. Hiring specifically trained and educated personnel is especially important given the study conducted by Lockie et al. (39), where the results indicated great fitness variation across recruits from 11 academy classes. Professionals would include those who are in supervisory coaching roles being a Certified Strength and Conditioning Specialist (CSCS), and those assisting the head CSCS should be at least a tactical strength and conditioning facilitator (TSAC-F). Coaches with a CSCS must follow established guidelines in their practice, especially as it relates to designing safe and effective training programs (57). The fitness diversity present in law enforcement recruits makes program design exceptionally challenging, even for those coaches who may have many years of experience and appropriate qualifications. Furthermore, good strength and conditioning coaches will operate via evidence- 
based practice (18), which should optimize fitness improvements for recruits, while also reducing the risk of injury.

The risk of injury for recruits during academy is a major issue for LEAs, especially given that many agencies are experiencing recruitment issues (66). Additionally, many agencies are attempting to increase the diversity of their workforce, and this often includes a targeted focus on recruiting and retaining more women $(19,74)$. As noted several times, female recruits and officers tend to demonstrate lesser fitness levels compared to their male counterparts $(4,5,7,14,37$ $39,43,44,46)$, which places greater importance on receiving appropriate physical training. If the training is inappropriate, injuries to recruits are more likely to occur (61), and this is problematic if a LEA is having issues with recruitment to begin with. It would be incumbent on LEA staff to ensure they retain as many recruits as possible, while still conducting a challenging program which minimizes injuries and maximizes job-relevant physical fitness. Strength and conditioning coaches can play an important role in reducing the injuries of their trainees (70). However, they should also be cognizant of the "hidden curriculum" of why certain practices are incorporated into police training (e.g. prepare them for specific aspects of their job) and not undermine the goals of the training staff. Rather, these factors should be considered, and the strength and conditioning professional should work collaboratively with the training staff to ensure the intended goals are addressed.

The major takeaway from this paper is the clear need for ability-based training for law enforcement recruits. Although academy class sizes can be large, there are certain strategies LEA staff and coaches can use. In athletic populations, fitness testing is often used to inform the training program 
(51). In law enforcement academies, although fitness assessment results may be used to reward recruits (35), it is generally not utilized in the design of the physical training program (32). McGuigan (51) asserted that fitness testing results can be used to identify the strengths and weaknesses of the individual, such that the coach can specifically target the weaknesses. Although this could be challenging with large classes, recruits could be pooled together in groups on the basis of their performance in muscular endurance (e.g. push-ups, sit-ups), strength (e.g. pull-ups), or aerobic (e.g. 2.4-km run) capacity assessments. Indeed, depending on the training modality, data can be used to categorize recruits into different ability groups. For example, with regards to aerobic conditioning, Cesario et al. (6) split a custody assistant class of 33 recruits into three groups based on $2.4-\mathrm{km}$ run time. Although the cut points were relatively arbitrary (i.e. the class was initially split into three equal groups), Cesario et al. (6) did note that the group split did make it easier to move recruits between groups if required.

Effective communication is essential for a strength and conditioning coach if they are teaching an individual a new movement or exercise (53). The communication required for coaching may be different to that typically provided during an academy class, and it is important for the strength and conditioning coach to be cognizant of this. There may be some unintended consequences if a strength and conditioning coach focuses more on coaching and teaching during training sessions with law enforcement recruits. If a more coaching focus is taken during physical training, this could influence the discipline exhibited by recruits (24). Holmes and Kornhauser (24) observed in their training academies that when the training approach shifted from a paramilitary-style to something closer to a more traditional coaching focus, recruits tended to display lesser discipline than they had in the past. Should a strength and conditioning coach take this approach, this must 
be communicated to the LEA staff so they understand why this is being done. Furthermore, strength and conditioning coaches should understand what LEA staff are attempting to teach recruits (e.g. stress inoculation, discipline, expected patterns of behavior) when they use autocratic communication styles (3), and situations where this may be more important.

There are a range of training modalities that could be used for law enforcement recruits $(6,9,32,35,54,61)$, and each could be modified relative to the ability of recruits in different ways. It is incumbent on the strength and conditioning coach to make these modifications within the constraints of the requirements set by LEA staff, academy class size, the available equipment, and the location. To provide support for the coach, this paper will provide some considerations and examples for two of the more popular training modalities used by law enforcement recruits aerobic conditioning and resistance training.

\section{AEROBIC CONDITIONING}

General recommendations to improve or maintain cardiorespiratory fitness in adults is that they engage in moderate-intensity cardiorespiratory exercise training for 30 minutes a day on 5 days per week, or vigorous-intensity cardiorespiratory exercise training for 20 minutes a day on 3 days per week (21). Depending on the structure of the academy, performing vigorous-intensity cardiorespiratory exercise for at least 20 minutes for many weeks of the academy should be attainable, especially considering that aerobic conditioning is a focus for many law enforcement academies. However, it should be noted that aerobic conditioning can take many forms and is not isolated to long continuous formation running. Table 1 displays some modalities that could be used 
for training aerobic capacity in law enforcement recruits that has been adapted from Reuter and Dawes (65).

\section{***INSERT TABLE 1 ABOUT HERE***}

During the earlier stages of academy, more continuous running may be utilized to provide a base of cardiorespiratory endurance via longer duration, and relatively lower intensity workouts (65). As the academy period progresses, fartlek and interval training could be introduced, as this would follow the NSCA's recommended progression of exercise intensity for aerobic conditioning, as this would follow the NSCA's recommended progression of exercise intensity for aerobic conditioning (65). Fartlek is a Swedish term that means 'speed play', and as defined by Reuter and Dawes (65) is an aerobic conditioning method that involves varying between long, slow distance pacing and pace/tempo training intensities. These could be implemented at least 1-2 times per week across academy to meet the suggested requirements for aerobic adaptations (65). One commonly used modality in law enforcement physical training is formation runs, which is a form of continuous running. As described by Cesario et al. (8), a formation run is historically a military tradition in which a group of service members run in an organized formation along a set route. The distance and pace of the run typically depends on the overall fitness level of the unit (i.e. greater fitness $=$ faster pace, or vice-versa). However, anecdotally the primary purpose of the run is the development of morale, so running speed is not always the primary focus. More importance is placed on the group staying together in a coherent formation. As a result, Cesario et al. (8) states that this may not be the best approach to develop aerobic fitness in recruits and may lead to more fit recruits being under-trained and less fit recruits over-trained. 
It would be very difficult for a strength and conditioning coach to individualize an aerobic conditioning session for every recruit in an academy class. However, one option is to divide the class into different ability groups (6). Interval training, perhaps more so than continuous running, could be structured in a way that makes this process easier. For example, fitness assessments such as the 201-m and 2.4-km run could be used to divide an academy class. Cesario et al. (6) presented a sample ability-based conditioning session for law enforcement recruits that used the $2.4-\mathrm{km}$ run to establish ability groups. In this instance, recruits were divided into three groups (low, intermediate, and high aerobic fitness) that performed runs around a grid. An adapted version of this grid can be seen in Figure 1. On two sides the recruits were to complete 'hard' runs, and then 'easy' recovery runs on the other sides. Depending on where the ability group started, each group should cover the distances in approximately the same time. The distances for each side of the grid can vary depending on space and what the coach wants for the session, but this at least provides a framework as to how an aerobic conditioning session can be moved towards individualization. Cesario et al. (6) recommended recruits perform two perimeters of the grid within a set (4 x hard runs, $4 \mathrm{x}$ easy runs), and 5-8 sets within a session. This would meet the time requirement needed for vigorous-intensity cardiorespiratory exercise training that could improve aerobic fitness (21). In addition, given the physical training is routinely scheduled for 1-2 hours during academy, this would allow for other forms of training (i.e. resistance or circuit training) within the one session.

\footnotetext{
***INSERT FIGURE 1 ABOUT HERE***
} 
The terms 'hard' and 'easy' are relatively arbitrary but are very practical within the law enforcement academy environment. This is because many LEAs will have limited access to monitoring equipment (e.g. GPS units, heart rate monitors, etc.) that can track training load and intensity (49). A simple way in which the strength and conditioning coach can track the intensity of training exercises and sessions in recruits is via rating or perceived exertion (RPE). The modified RPE scale 0-10 category-ratio scale was originally designed for use in resistance training (20), but has also been used for aerobic exercise (28). This scale has been utilized by (1) and recommended for (52) firefighters, so would have application for law enforcement recruits as well. The approximate RPE for the 'hard' and 'easy' runs can be seen in Figure 1. If the recruits have been accurately divided into ability groups, with appropriate application of work and recovery, the strength and conditioning coach could attain relatively similar perceived intensity across their recruits, regardless of fitness level. Additionally, the talk test could be a valid method to measure exercise intensity in the field for recruit populations. Woltmann et al. (73) found that the ability to talk during exercise could be linked to indicators of intensity including heart rate, blood lactate, and RPE.

\section{RESISTANCE TRAINING}

General recommendations for the use of resistance training to improve strength can vary by experience. With regards to training frequency, it has been suggest that novices (training age of $<2$ months) should train 1-2 days per week; intermediate lifters (training age of 2-6 months) should training $\leq 2-3$ times per week; and advanced lifters (training age of $\geq 12$ months) can train $\geq 3-4$ times per week (67). During a law enforcement academy, the entire class will generally be training together, so the strength and conditioning coach should consider building a program that could 
feature 3-4 resistance training sessions per week, depending on the timetable for the class. Furthermore, given the results detailed by previous research $(39,42,48)$, it is likely a law enforcement academy class will be a mix of novice, intermediate, and advanced lifters. This would make scheduling a resistance training program for all recruits very difficult. Further, to minimize instruction basic exercise should traditionally be the focus, as more complicated lifts (e.g. Olympic weightlifting movements) may take too long to instruct given the time frame allotted and may actually detract from the development of physical conditioning.

Due to time constraints, full-body programs will likely be more efficient during academy. The constraints of academy may also mean that circuit training is a popular modality to use for recruits $(54,58)$. Circuit training involves performing a series of exercises where the rest time between exercises can vary depending on the goal of the session (2). For example, if lighter loads (relative to the effort and muscular force exerted) are used ( $\geq 12$ repetitions), then rest times can be shorter ( $\leq 30 \mathrm{~s})$; if heavier loads are used in a circuit ( $<6$ repetitions), then the rest times should be extended (2-5 minutes) (67). In this way, the strength and conditioning coach could design a circuit-based session that caters towards recruits with different ability levels and lifting experience. Furthermore, during the sessions where heavier loads are used, recruits could be paired where the resting recruit can act as a safety 'spotter' and motivator, thereby using the longer rest periods to increase safety and build teamwork. Moreno et al. (54) has detailed an ability-based circuit training session that could be used to develop strength in law enforcement recruits. For this paper, a program adapted from several sources has been presented in Table $2(23,52,54)$. Equipment can be a limiting factor at law enforcement academies, and this has been considered in this program with the use of pushups and pull-ups. The reader is directed to Moreno et al. (54) for detailed descriptions of the 
assisted and resisted versions of these exercises. For the lower-body exercises, if traditional lifting equipment is not available, the strength and conditioning coach should take advantage of nontraditional equipment that may be available at a LEA that could provide resistance (e.g. ammunition cans, duty bags, body armor) (54). Performing unilateral exercises (e.g. single-leg squats, rear-foot elevated split squats) and manual resistance exercises may also be ways to accommodate for equipment constraints.

***INSERT TABLE 2 ABOUT HERE***

Abdominal muscular endurance and lumbo-pelvic stability are also an important consideration for law enforcement recruits, and were included in the example program (Table 4). This is especially important considering the load carriage demands that recruits will encounter when they graduate academy and become officers (16). As sit-ups are a staple within law enforcement fitness testing $(7,9,10,12,15,35,37,39,46,59)$, they are often performed during academy. However, there are a range of different (and arguably better) options for training these muscle groups available to the strength and conditioning coach. Specific to first responder recruits, Gonzales and Lockie (23) provided several example exercises that could be scaled up or down depending on the strength and ability level of the recruit. For exercises involving isometric holds, McGill (50) recommends a duration of $10 \mathrm{~s}$ or less, and increasing the number of repetitions (rather than duration) to progress the exercise.

\section{CONCLUSIONS}


This paper involved the review of appropriate literature to highlight the wide variation in muscular endurance and strength, and anaerobic and aerobic capacity between individual recruits. This wide diversity emphasizes the need for individualization, or shifting the focus to ability-based training, for recruits during academy. Agencies should consider utilizing trained professionals (e.g. CSCS, and individuals with a TSAC-F to work with a CSCS) to design effective training programs for their recruits, as this should optimize fitness improvements while reducing injury risk. For the strength and conditioning coach working with recruits, there are specific law enforcement considerations that they must be conscious of when designing their training programs. Programs will need to be implemented within the constraints of the academy timetable, available equipment, and location. Effective communication between the coach and LEA staff is also essential, given the socialization aspect of physical training for law enforcement recruits. Nevertheless, strength and conditioning coaches should attempt to adapt their training programs to meet recruits where they currently are with their fitness and abilities, and then progress the program appropriately during academy.

Conflicts of Interest and Source of Funding: The authors report no conflicts of interest and no source of funding.

\section{REFERENCES}

1. Abel MG, Mortara AJ, and Pettitt RW. Evaluation of circuit-training intensity for firefighters. J Strength Cond Res 25: 2895-2901, 2011. 
2. Alcaraz PE, Sanchez-Lorente J, and Blazevich AJ. Physical performance and cardiovascular responses to an acute bout of heavy resistance circuit training versus traditional strength training. J Strength Cond Res 22: 667-671, 2008.

3. Berg BL. First day at the police academy: Stress-Reaction-Training as a screening-out technique. J Contemp Crim Justice 6: 89-105, 1990.

4. Bloodgood AM, Dawes JJ, Orr RM, Stierli M, Cesario KA, Moreno MR, Dulla JM, and Lockie RG. Effects of sex and age on physical testing performance for law enforcement agency candidates: Implications for academy training. J Strength Cond Res: doi:10.1519/jsc.0000000000003207, in press.

5. Boyce RW, Jones GR, Schendt KE, Lloyd CL, and Boone EL. Longitudinal changes in strength of police officers with gender comparisons. $J$ Strength Cond Res 23: 2411-2418, 2009.

6. Cesario, K, Moreno, M, Bloodgood, A, and Lockie, R. A sample ability-based conditioning session for law enforcement and correctional recruits. TSAC Report 52: 6-11, 2019.

7. Cesario KA, Dulla JM, Moreno MR, Bloodgood AM, Dawes JJ, and Lockie RG. Relationships between assessments in a physical ability test for law enforcement: Is there redundancy in certain assessments? Int J Exerc Sci 11: 1063-1073, 2018.

8. Cesario, KA, Moreno, MR, Bloodgood, AM, Dulla, JM, and Lockie, RG. Heart rate responses of a custody assistant class to a formation run during academy training, in: Southwest American College of Sports Medicine's 37th Annual Meeting Long Beach, CA, USA, 2017.

9. Cocke C, Dawes J, and Orr RM. The use of 2 conditioning programs and the fitness characteristics of police academy cadets. J Athl Train 51: 887-896, 2016. 
10. Crawley AA, Sherman RA, Crawley WR, and Cosio-Lima LM. Physical fitness of police academy cadets: Baseline characteristics and changes during a 16-week academy. $J$ Strength Cond Res 30: 1416-1424, 2016.

11. Dawes JJ, Kornhauser CL, Crespo D, Elder CL, Lindsay KG, and Holmes RJ. Does body mass index influence the physiological and perceptual demands associated with defensive tactics training in state patrol officers? Int J Exerc Sci 11: 319-330, 2018.

12. Dawes JJ, Lindsay K, Bero J, Elder C, Kornhauser C, and Holmes R. Physical fitness characteristics of high vs. low performers on an occupationally specific physical agility test for patrol officers. J Strength Cond Res 31: 2808-2815, 2017.

13. Dawes JJ, Lockie RG, Orr RM, Kornhauser C, and Holmes RJ. Initial fitness testing scores as a predictor of police academy graduation. J Aust Strength Cond 27: 30-37, 2019.

14. Dawes JJ, Orr RM, Flores RR, Lockie RG, Kornhauser C, and Holmes R. A physical fitness profile of state highway patrol officers by gender and age. Ann Occup Environ Med 29: doi:10.1186/s40557-40017-40173-40550, 2017.

15. Dawes JJ, Orr RM, Siekaniec CL, Vanderwoude AA, and Pope R. Associations between anthropometric characteristics and physical performance in male law enforcement officers: A retrospective cohort study. Ann Occup Environ Med 28: doi:10.1186/s40557-4001640112-40555, 2016.

16. dos Santos MC, Krueger E, and Neves EB. Electromyographic analysis of postural overload caused by bulletproof vests on public security professionals. Res Biomed Eng 33: 175-184, 2017.

17. Drew J, Carless SA, and Thompson BM. Predicting turnover of police officers using the sixteen personality factor questionnaire. J Crim Justice 36: 326-331, 2008. 
18. English KL, Amonette WE, Graham M, and Spiering BA. What is "evidence-based" strength and conditioning? Strength Cond J34: 19-24, 2012.

19. Felkenes GT, Peretz P, and Schroedel JR. An analysis of the mandatory hiring of females. Women Crim Justice 4: 31-63, 1993.

20. Foster C, Florhaug JA, Franklin J, Gottschall L, Hrovatin LA, Parker S, Doleshal P, and Dodge C. A new approach to monitoring exercise training. J Strength Cond Res 15: 109$115,2001$.

21. Garber CE, Blissmer B, Deschenes MR, Franklin BA, Lamonte MJ, Lee IM, Nieman DC, and Swain DP. American College of Sports Medicine position stand. Quantity and quality of exercise for developing and maintaining cardiorespiratory, musculoskeletal, and neuromotor fitness in apparently healthy adults: guidance for prescribing exercise. Med Sci Sports Exerc 43: 1334-1359, 2011.

22. Gebhardt, DL, Baker, TA, and Polaki, J. Job Analysis for the Los Angeles County Sheriff's Department Patrol Deputy Assignment. Beltsville, MD: Human Performance Systems, Inc., 2008.

23. Gonzales, C and Lockie, R. Abdominal and lumbo-pelvic stability exercises for first responders. TSAC Report 55: 12-20, 2019.

24. Holmes, RJ and Kornhauser, CL. Building Injury Free Tactical Athletes: A Repeatable Model for Police Academy Recruit Training, in: TSAC Annual Training. Norfolk, VA, 2018.

25. Horn TS, Bloom P, Berglund KM, and Packard S. Relationship between collegiate athletes’ psychological characteristics and their preferences for different types of coaching behavior. Sport Psychol 25: 190, 2011. 
26. Jones BH, Bovee MW, Harris JM, 3rd, and Cowan DN. Intrinsic risk factors for exerciserelated injuries among male and female army trainees. Am J Sports Med 21: 705-710, 1993.

27. Kayihan G, Ersöz G, Özkan A, and Koz M. Relationship between efficiency of pistol shooting and selected physical-physiological parameters of police. Policing: Intl J Police Strat \& Mgmt 36: 819-832, 2013.

28. Kilpatrick MW, Robertson RJ, Powers JM, Mears JL, and Ferrer NF. Comparisons of RPE before, during, and after self-regulated aerobic exercise. Med Sci Sports Exerc 41: 682$687,2009$.

29. Knapik JJ, Grier T, Spiess A, Swedler DI, Hauret KG, Graham B, Yoder J, and Jones BH. Injury rates and injury risk factors among Federal Bureau of Investigation new agent trainees. BMC Public Health 11: 920, 2011.

30. Lagestad P and van den Tillaar R. A comparison of training and physical performance of police students at the start and the end of three-year police education. $J$ Strength Cond Res 28: 1394-1400, 2014.

31. Lentz L, Randall JR, Guptill CA, Gross DP, Senthilselvan A, and Voaklander D. The association between fitness test scores and musculoskeletal injury in police officers. Int $J$ Environ Res Public Health 16: doi:10.3390/ijerph16234667, 2019.

32. Lockie RG, Balfany K, Bloodgood AM, Moreno MR, Cesario KA, Dulla JM, Dawes JJ, and Orr RM. The influence of physical fitness on reasons for academy separation in law enforcement recruits. Int $J$ Environ Res Public Health 16: doi.org/10.3390/ijerph16030372, 2019. 
33. Lockie RG, Balfany K, Denamur JK, and Moreno MR. A preliminary analysis of relationships between a $1 \mathrm{RM}$ hexagonal bar load and peak power with the tactical task of a body drag. J Hum Kinet 68: 157-166, 2019.

34. Lockie, RG, Cesario, KA, Bloodgood, AM, and Moreno, MR. Heart rate response to psychological stress: Importance of stress education for law enforcement recruits. TSAC Report 51: 4-7, 2018.

35. Lockie RG, Dawes JJ, Balfany K, Gonzales CE, Beitzel MM, Dulla JM, and Orr RM. Physical fitness characteristics that relate to Work Sample Test Battery performance in law enforcement recruits. Int J Environ Res Public Health 15: doi:10.3390/ijerph15112477, 2018.

36. Lockie RG, Dawes JJ, Kornhauser CL, Holmes R, and Orr RM. Young officers drive faster, but older officers crash less: Results of a police pursuit driving course. Police Sci Aust NZ J Evid Based Polic 3: 37-41, 2018.

37. Lockie RG, Dawes JJ, Kornhauser CL, and Holmes RJ. Cross-sectional and retrospective cohort analysis of the effects of age on flexibility, strength endurance, lower-body power, and aerobic fitness in law enforcement officers. $J$ Strength Cond Res 33: 451-458, 2019.

38. Lockie RG, Dawes JJ, Moreno MR, Cesario KA, Balfany K, Stierli M, Dulla JM, and Orr RM. Relationship between the $20-\mathrm{m}$ multistage fitness test and $2.4-\mathrm{km}$ run in law enforcement recruits. $J$ Strength Cond Res: doi:10.1519/jsc.0000000000003217, in press.

39. Lockie RG, Dawes JJ, Orr RM, and Dulla JM. Recruit fitness standards from a large law enforcement agency: Between-class comparisons, percentile rankings, and implications for physical training. J Strength Cond Res 34: 934-941, 2020. 
40. Lockie RG, Dawes JJ, Orr RM, Stierli M, Dulla JM, and Orjalo AJ. An analysis of the effects of sex and age on upper- and lower-body power for law enforcement agency recruits prior to academy training. J Strength Cond Res 32: 1968-1974, 2018.

41. Lockie RG, Dulla JM, Stierli M, Cesario KA, Moreno MR, Bloodgood AM, Orr RM, and Dawes JJ. Associations between body mass and physical fitness assessments in male custody assistants from a law enforcement agency. J Aust Strength Cond 26: 43-49, 2018.

42. Lockie RG, Fazilat B, Dulla JM, Stierli M, Orr RM, Dawes JJ, and Pakdamanian K. A retrospective and comparative analysis of the physical fitness of custody assistant classes prior to academy training. Sport Exerc Med Open J 4: 44-51, 2018.

43. Lockie RG, Hernandez JA, Moreno MR, Dulla JM, Dawes JJ, and Orr RM. 2.4-km run and 20-m multistage fitness test relationships in law enforcement recruits after academy training. J Strength Cond Res 34: 942-945, 2020.

44. Lockie RG, Moreno MR, Cesario KA, McGuire MB, Dawes JJ, Orr RM, and Dulla JM. The effects of aerobic fitness on day one physical training session completion in law enforcement recruits. J Trainol 8: 1-4, 2019.

45. Lockie RG, Orr RM, Moreno MR, Dawes JJ, and Dulla JM. Time spent working in custody influences Work Sample Test Battery performance of Deputy Sheriffs compared to recruits. Int J Environ Res Public Health 16: doi:10.3390/ijerph16071108, 2019.

46. Lockie RG, Orr RM, Stierli M, Cesario KA, Moreno MR, Bloodgood AM, Dulla JM, and Dawes JJ. The physical characteristics by sex and age for custody assistants from a law enforcement agency. J Strength Cond Res 33: 2223-2232, 2019.

47. Lockie RG, Ruvalcaba TR, Stierli M, Dulla JM, Dawes JJ, and Orr RM. Waist circumference and waist-to-hip ratio in law enforcement agency recruits: Relationship to 
performance in physical fitness tests. $J$ Strength Cond Res: doi:10.1519/jsc.0000000000002825, in press.

48. Lockie RG, Stierli M, Dawes JJ, Cesario KA, Moreno MR, Bloodgood AM, Orr RM, and Dulla JM. Are there similarities in physical fitness characteristics of successful candidates attending law enforcement training regardless of training cohort? J Trainol 7: 5-9, 2018.

49. Maupin D, Schram B, and Orr R. Tracking training load and its implementation in tactical populations: A narrative review. Strength Cond J 41: 1-11, 2019.

50. McGill S. Core training: Evidence translating to better performance and injury prevention. Strength Cond J 32: 33-46, 2010.

51. McGuigan MR. Principles of Test Selection and Administration, in: Essentials of Strength Training and Conditioning. GG Haff, NT Triplett, eds. Champaign, IL: Human Kinetics, 2015, pp 249-258.

52. McGuire, M, Moreno, M, and Lockie, R. Practical exercise programming for Wildland Fire Suppression Aids. TSAC Report 54: 22-35, 2019.

53. Moore EWG, Quartiroli A, Zakrajsek R, and Eckenrod M. Increasing collegiate strength and conditioning coaches' communication of training performance and process goals with athletes. Strength Cond J 41: 18-24, 2019.

54. Moreno, M, Cesario, K, Bloodgood, A, and Lockie, R. Circuit strength training with ability-based modifications for law enforcement recruits. TSAC Report 51: 26-33, 2018.

55. Moreno MR, Dulla JM, Dawes JJ, Orr RM, Cesario KA, and Lockie RG. Lower-body power and its relationship with body drag velocity in law enforcement recruits. Int J Exerc Sci 12: 847-858, 2019. 
56. Myers CJ, Orr RM, Goad KS, Schram BL, Lockie R, Kornhauser C, Holmes R, and Dawes JJ. Comparing levels of fitness of police officers between two United States law enforcement agencies. Work 63: 615-622, 2019.

57. National Strength and Conditioning Association. NSCA strength and conditioning professional standards and guidelines. Strength Cond J 39: 1-24, 2017.

58. Norvell $\mathrm{N}$ and Belles D. Psychological and physical benefits of circuit weight training in law enforcement personnel. J Consult Clin Psychol 61: 520-527, 1993.

59. Orr R, Dawes JJ, Pope R, and Terry J. Assessing differences in anthropometric and fitness characteristics between police academy cadets and incumbent officers. J Strength Cond Res 32: 2632-2641, 2018.

60. Orr R, Pope R, Stierli M, and Hinton B. Grip strength and its relationship to police recruit task performance and injury risk: A retrospective cohort study. Int J Environ Res Public Health 14: doi:10.3390/ijerph14080941, 2017.

61. Orr RM, Ford K, and Stierli M. Implementation of an ability-based training program in police force recruits. J Strength Cond Res 30: 2781-2787, 2016.

62. Patton JF, Morgan WP, and Vogel JA. Perceived exertion of absolute work during a military physical training program. Eur J Appl Physiol Occup Physiol 36: 107-114, 1977.

63. Peace Officer Standards and Training. Work Sample Test Battery Proctor Manual, 2012. Available from $\quad$ https://post.ca.gov/post_docs/regulationnotices/201205/WrkSmplTestBattryProctrMan.pdf. Accessed August 15, 2018.

64. Piantanida NA, Knapik JJ, Brannen S, and O'Connor F. Injuries during Marine Corps officer basic training. Mil Med 165: 515-520, 2000. 
65. Reuter BJ and Dawes JJ. Program Design and Technique for Aerobic Endurance Training, in: Essentials of Strength Training and Conditioning. GG Haff, NT Triplett, eds. Champaign, IL: Human Kinetics, 2016, pp 559-582.

66. Roufa, T. Why Police Departments Are Facing Recruitment Problems, 2018. Available from https://www.thebalancecareers.com/why-police-departments-are-facingrecruitment-problems-974771. Accessed July 5, 2019.

67. Sheppard JM and Triplett NT. Program Design for Resistance Training, in: Essentials of Strength Training and Conditioning. GG Haff, NT Triplett, eds. Champaign, IL: Human Kinetics, 2016, pp 439-470.

68. Shusko M, Benedetti L, Korre M, Eshleman EJ, Farioli A, Christophi CA, and Kales SN. Recruit fitness as a predictor of police academy graduation. Occup Med 67: 555-561, 2017.

69. Statler T and Brown V. Facility Policies, Procedures, and Legel Issues, in: Essentials of Strength Training and Conditioning. GG Haff, NT Triplett, eds. Champaign, IL: Human Kinetics, 2016, pp 641-656.

70. Talpey SW and Siesmaa EJ. Sports injury prevention: The role of the strength and conditioning coach. Strength Cond J 39: 14-19, 2017.

71. Tomes CD, Sawyer S, Orr R, and Schram B. Ability of fitness testing to predict injury risk during initial tactical training: A systematic review and meta-analysis. Inj Prev 26: 67-81, 2020.

72. Trank TV, Ryman DH, Minagawa RY, Trone DW, and Shaffer RA. Running mileage, movement mileage, and fitness in male U.S. Navy recruits. Med Sci Sports Exerc 33: 1033$1038,2001$. 
73. Woltmann ML, Foster C, Porcari JP, Camic CL, Dodge C, Haible S, and Mikat RP. Evidence that the talk test can be used to regulate exercise intensity. $J$ Strength Cond Res 29: 1248-1254, 2015.

74. Zhao JS, He N, and Lovrich NP. Pursuing gender diversity in police organizations in the 1990s: A longitudinal analysis of factors associated with the hiring of female officers. Police Q 9: 463-485, 2006.

\section{FIGURE LEGEND}

Figure 1: Grid that could be used for a conditioning session that utilizes ability-based groups. Adapted from Cesario et al. (6). 
Table 1: Examples of aerobic (and some anaerobic) conditioning modalities for law enforcement recruits, which have been adapted from Reuter and Dawes (65). It should be noted that these modalities could be used for different modes of aerobic exercise (e.g. running, stepping, stair climbing, cycling, etc.).

\begin{tabular}{cccc}
\hline Training Type & Frequency Per Week & Duration & Intensity \\
\hline Continuous & $1-2$ & $\sim 30-120$ min & Submaximal \\
Fartlek & 1 & $\sim 20-60$ min & Varies between \\
& & & submaximal- \\
Interval & $1-2$ & $3-5$ min & Close to maximal \\
High-Intensity & & (work:rest ratio 1:1) & \\
Interval & 1 & (wo-90 s & Maximal effort \\
& & & \\
\hline
\end{tabular}


Table 2: Example circuit-based resistance training session. Time between stations can be manipulated depending on training session goals.

\begin{tabular}{cccc}
\hline & Novice & Intermediate & Advanced \\
& Learning & Transitional & Maximum Strength \\
\hline Target Repetitions & $12-15$ & $6-12$ & $\leq 6$ \\
Exercises & & & \\
Squat & Body weight & Load allowing for goal & Load allowing for goal \\
(Lower-Body) & & repetitions & repetitions \\
Push-ups & Assisted & Body weight & Resisted \\
(Upper-Body) & & &
\end{tabular}

$\begin{array}{cccc}\text { Romanian Deadlift } & \text { PVC pipe or light } & \text { Load allowing for goal } & \text { Load allowing for goal } \\ \text { (Lower-Body) } & \text { load to learn hinge } & \text { repetitions } & \text { repetitions } \\ & \text { movement } & & \end{array}$

Pull-ups

(Upper-Body)

Assisted Body weight $\quad$ Resisted

Step-ups

(Lower-Body)

Abdominals
Body weight

Load allowing for goal Load allowing for goal repetitions repetitions

Plank

Side Plank (feet stacked to progress, staggered to regress) 